\title{
CLOSED REDUCTION AND PERCUTANEOUS KIRSCHNER WIRE FIXATION OF DISPLACED SUPRACONDYLAR FRACTURES OF HUMERUS IN CHILDREN
}

\author{
Deepak Kumar1, Kanwarjeet Singh Saluja² \\ ${ }^{1}$ Assistant Professor, Department of Orthopaedics, Rama Medical College Hospital and Research Centre, Mandhana. \\ ${ }^{2}$ Senior Resident, Department of Orthopaedics, Rama Medical College Hospital and Research Centre, Mandhana.
}

\begin{abstract}
Displaced supracondylar fractures have a very sinister presentation with a high probability of neurovascular injuries. They also have a high rate of displacement and if not reduced and stabilized in optimal position may lead to serious residual deformity. The purpose of this work was to evaluate the results of stabilization of these fractures by closed reduction and percutaneous Kirschner wire fixation. Twenty-one males and seven females with ages ranging from 3 to 14 years who required closed reduction and internal fixation using percutaneous Kirschner wire for fresh displaced supracondylar fractures of humerus between October 2012 and November 2014 were selected. The Kirschner wires were passed percutaneously under C-arm control from the lateral epicondyle in varying geometry or configuration to achieve fracture stability. Each patient was followed up for at least two years and results were graded using the Flynn's criteria. They were graded as excellent 24 (85.72\%) cases, good in $2(10.71 \%)$ cases and only $01(03.57 \%)$ case had a poor result. There were no fair results at the end of final follow up. For acceptable closed reduction Baumann's angle should be within $4^{\circ}$ of the normal side and fracture fixation should be done with minimum of 3 Kirschner wires. This method is safe even in presence of swelling with shorter hospital stay and consistently satisfactory results considering cosmetic and functional outcome.
\end{abstract}

\section{KEYWORDS}

Anatomical Reduction- Percutaneous Fixation- Baumann's angle.

HOW TO CITE THIS ARTICLE: Kumar D, Saluja KS. Closed reduction and percutaneous Kirschner wire fixation of displaced supracondylar fractures of humerus in children. J. Evolution Med. Dent. Sci. 2016;5(21):1104-1105, DOI: 10.14260/jemds/2016/256

\section{INTRODUCTION}

\begin{tabular}{|l|l|}
\hline Excellent & $\begin{array}{l}\text { Loss in carrying angle }<5^{\circ} \text { or Limitation of } \\
\text { elbow movements }<5\end{array}$ \\
\hline Good & $\begin{array}{l}\text { Loss in carrying angle } 6^{\circ}-10^{\circ} \text { or Limitation of } \\
\text { elbow movements from } 6-10^{\circ}\end{array}$ \\
\hline Fair & $\begin{array}{l}\text { Loss in carrying angle } 10^{\circ}-15^{\circ} \text { or Limitation of } \\
\text { elbow movements from } 10^{\circ}-15^{\circ}\end{array}$ \\
\hline Poor & $\begin{array}{l}\text { Loss in carrying angle }>15^{\circ} \text { or Limitation of } \\
\text { elbow movements }>15^{\circ}\end{array}$ \\
\hline \multicolumn{2}{|c|}{ Table 1: Grading of Results (Flynn et al. 1974) } \\
\hline
\end{tabular}

\section{PATIENTS AND METHODS}

In a prospective study, closed reduction and percutaneous Kirschner wire fixation for displaced supracondylar fractures of the humerus was done. The inclusion criteria were open humeral growth plate and Grade II and III displaced fractures. In the presence of a gross swelling, Dunlop traction was applied and surgery was done after the swelling subsided. Traction was given under general anaesthesia with the elbow in extension and forearm in supination, longitudinal traction was given with an assistant applying counter traction. The fracture was thus disimpacted and then the medial or lateral displacement was corrected by applying a varus or valgus force.

The angulations were corrected by flexing the elbow with continued traction.

Financial or Other, Competing Interest: None.

Submission 18-01-2016, Peer Review 17-02-2016,

Acceptance 22-02-2016, Published 12-03-2016.

Corresponding Author:

Deepak Kumar,

97 'E' Mandir Road, Panki,

Kanpur-208020.

E-mail: dkortho212@gmail.com

DOI: $10.14260 /$ jemds $/ 2016 / 256$
During the entire procedure, the radial pulse was observed at regular intervals. X-rays were then taken in anteroposterior (Shoot through) and lateral views and the reduction was assessed. While taking the lateral views, special attention was given to rotate the X-ray tube rather than rotating the arm. The assessment of reduction was done clinically by assessing the extent of flexion and by assessing the carrying angle prior to flexion of the elbow. Radiological assessment of reduction was done by calculation of Baumann's angle.

If the reduction was clinicoradiologically acceptable, the assistant held the elbow in the same position and the Kirschner wires (1.5-2.0 mm) were passed from the lateral epicondyle to avoid damage to the ulnar nerve. A minimum of two and a maximum of three wires were used. The direction of the Kirschner wires were $40^{\circ}$ from the long axis of the humerus medially and $10^{\circ}$ posteriorly. Care was taken to see that they engaged in the far cortex, which ensured stable fixation. In selected cases the Kirschner wires were passed in varying configurations like crossed, parallel, divergent or crossed parallel. In parallel fixation, the Kirschner wires were separated by a distance of at least $10 \mathrm{~mm}$, so that they acted as separate Kirschner wires. The fixation was again assessed radiologically and once acceptable the Kirschner wires were cut flush with the skin and bent outside the skin.

Limb was protected and kept in above elbow slab with 80-100 flexion with arm to chest strapping and were discharged after 72-96 hrs after pinning. The patients were called for the first follow up after 4-6 weeks of surgery. On clinicoradiological union, the Kirschner wires were removed and gentle active mobilization was started.

\section{OBSERVATIONS}

The age of patients ranged from 3-14 years with a mean age of 6 years. There were 21 males and 7 females. The left elbow was involved in 21 cases and right in 7 . The usual cause was a fall 
on the outstretched hand. Twenty-seven cases had simple fractures and only one case had a compound injury following a vehicular accident. All the patients had pain and swelling around the joint and movements of the affected elbow were grossly restricted and painful. Of the 28 patients, 25 had posteromedial type of displacement and 3 had posterolateral displacement. Four had nerve injuries at the time of presentation, out of which two had anterior interosseous nerve injury and one each had involvement of radial nerve and ulnar nerve. All these cases recovered completely within 2-6 months. Nine patients presented with a feeble radial pulse and huge swelling of the arm and elbow. All these patients were put on the Dunlop traction and were operated after the swelling subsided and vascularity was good. Colour Doppler studies were done in these patients and revealed spasm of brachial artery in the adjacent area of fracture. Adequate blood flow was restored after reduction and no exploration was required.

The time required for clinicoradiological union ranged from 3-6 weeks with an average of 4 weeks. The carrying angles on follow up were measured and compared with that of the normal. The average carrying angle was $10.65^{\circ}$ (Range 415) on the affected side and $12.62^{\circ}$ (Range 8-18) on the normal side. Three patients had loss of reduction. Granuloma formation and Kirschner wire loosening were observed in one patient each respectively. Rest of the patients did not have any complications. Twenty-six patients had a loss of range of flexion within 50 of the normal side and only two had a loss of range of flexion within $5-10^{\circ}$ of the normal side.

Each patient was followed up for at least two years and results were graded using the Flynn's criteria (Table I). We had excellent results in $24(85.72 \%)$ cases, good in 3 cases $(10.71 \%)$ and only $01(3.57 \%)$ case had a poor result at the final follow up. The poor result was due to technical error in pinning resulting in cubitus varus of $15^{\circ}$.

\section{DISCUSSION}

Supracondylar fracture is a common fracture seen in the paediatric population. Anatomical reduction and its maintenance is essential for obtaining excellent results. Its management poses a number of problems like cubitus varus, nerve palsies and Volkmann's ischemic contracture. Various methods of treatment have been advocated in the form of closed reduction and above elbow plaster cast application. ${ }^{1}$ skin/skeletal traction. ${ }^{2}$ primary closed reduction and percutaneous pinning and open reduction and internal fixation by Kirschner wires. ${ }^{3}$ Of these methods used traction requires a longer period of hospital stay, but is less reliable in children and has no added advantage over immediate closed reduction and percutaneous pinning except in cases who has gross swelling. Infection and joint stiffness usually are the problems in open reduction. Hence closed reduction and percutaneous pinning is the preferred treatment in Grade II and Grade III displaced supracondylar fractures.

The technique of pinning is a matter of controversy and technical excellence. Cross pinning is theoretically more stable biomechanically construct, but it adds to the risk of ulnar nerve injury, especially when fracture is associated with swelling. Direct injury to ulnar nerve as well as delayed neuropathy possibly due to stretching of nerve over the medial pin is a known complication. ${ }^{4}$ Equally stable construct is lateral pinning, provided the lateral wires are at least $10 \mathrm{~mm}$ apart and they cross over in the proximal fragment and have purchase in the far cortex. ${ }^{5}$ Otherwise, these lateral wires act as a single wire and allow rotation of the distal fragment.

Aronson and Prager emphasized the importance of Baumann's angle for accepting the reduction and showed excellent results. ${ }^{6}$ They reported that if Baumann's angle of the injured extremity is within $4^{\circ}$ of the normal side, then there will be no cubitus varus deformity. Many studies have recommended Kirschner wire from the lateral condyle in either parallel or crossed or divergent configurations to minimize iatrogenic ulnar nerve injury. ${ }^{7}$ Immobilization of the involved extremity after closed reduction and percutaneous pin fixation with above elbow, plaster slab immobilization with arm to chest strapping gives additional rotational stability at the fracture site and prevent redisplacement. 4 Complications such as ulnar nerve palsy $(1.38 \%)$, loss of reduction $(2.77 \%)$, Kirschner wire expulsion $(1.38 \%)$ and heterotopic ossification (1.38\%) have been reported..$^{8}$ In the present series, there was pin loosening and granuloma formation in one $(3.45 \%)$ case each. Cubitus varus deformity has been universally considered as a poor indicator of the result, irrespective of the treatment used. ${ }^{9}$ The main cause of the loss of carrying angle can be attributed to improper reduction or loss of reduction postoperatively.

Thus, it is a safe method even in the presence of swelling and displacement, resulting in a shorter hospital stay and a consistently satisfactory functional outcome and cosmesis even in less experienced hands.

\section{REFERENCES}

1. Gartland J. Management of Supracondylar Fractures in Children. Surg Gvnecol Obste 1959:109(2):145-54.

2. Dunlop J. Transcondylar fracture of the humerus in children. J Bone Joint Surg Am 1939;21(1):59-73.

3. Davis RT, Gorezyca JT, Pugh K. Supracondylar humerus fracture in children, Comparison of operative treatment method. Clin Orthop 2000;376:49-55.

4. Mazda K, Boggione C, Fitoussi F, et al. Systematic pinning of displaced extension type of supracondylar fractures of the humerus in children - a prospective study of 116 consecutive patients. J Bone Joint Surg Br 2001:83(6):888893.

5. Topping RE, Blanco JS, Davis TJ. Clinical evaluation of crossed pin versus lateral pin fixation of the displaced supracondylar humeral fracture. J Pediatr Orthop 1995;15(4):435-439.

6. Aronson DD, Prager BI. Supracondylar fracture of the humerus in children. A modified technique of closed pinning. Clin Orthop 1985;15:174-184.

7. Arino VL, liuch EE, Ramirez AM, et al. Percutaneous fixation ofsupracondylarfracture of the humerus in children. J Bone Joint Surg Anm 1977;59(7):914-916.

8. Flynn JC, Matthews JG, Benoit RL. Blind pinning of displaced supracondylar fractures of the Humerus in the children. Sixteen years' experience with long-term followup. J Bone Joint Surgf Am 1974;56(2):263-272.

9. Pirone AM, Graham HK, Karbich JI. Management of displaced extension type supracondylar fractures of the humerus in children. J Bone Joint Surg Br 1988;70-A:641650 . 